\title{
The Use of Artefact Production to Achieve Learning Objectives in a Second-Year Zoology Course at an Institute of Higher Learning
}

\author{
Andre D. Daniels \\ Centre of Information, Education and Communication Technology \\ University of the Western Cape, P. Bag X17, Bellville 7535, South Africa \\ addaniels@uwc.ac.za \\ Lorna B. Holtman \\ Division for Postgraduate Studies, University of the Western Cape, \\ P. Bag X17, Bellville 7535, South Africa \\ Iholtman@uwc.ac.za
}

\section{Doi:10.5901/mjss.2014.v5n6p263}

\begin{abstract}
The research work provides a case study of an effective use of e-learning to supplement face-to-face teaching-and-learning in a second-year Zoology course at the University of the Western Cape. This work was undertaken as part of a study to develop a pedagogy for effectively introducing and integrating artefact-production as a teaching-and-learning technique. The study is underpinned by the theoretical framework of Activity theory and Constructivism. Data sources include observations and interviews conducted with students as well as the artefacts produced using Microsoft Producer and PowerPoint (CD and DVD presentations). The report highlights the impact of the construction of an artefact on the learning experience of students in the course and demonstrates the value of having students use technology to construct their own learning, rather than using technology purely to interact with artefacts developed by others. The report focuses on the dynamic interaction within student groups with varying levels of computer literacy. The study concludes that technology is best introduced in a well-structured course where excitement is derived from the content. Moreover, that the appropriate use of technology serves to increase the retention of information by providing multiple and varied opportunities for interaction with subject content. Although the study was undertaken in a face-to-face classroom, the results can be applied to e-learning supported by Web technologies. This can be achieved by creating artefacts that can be viewed and manipulated in a web browser, and by providing online tools to facilitate their creation and use, as well as for providing assessment and feedback.
\end{abstract}

Keywords: activity theory, artefact production, e-learning, multimedia

\section{Introduction}

The University of the Western Cape (UWC) has adopted an e-learning strategy with a strategic objective to,

Provide and promote the technology to enable UWC to produce graduates who are able to use technology to find, understand, apply, analyze, synthesize, evaluate and report on information from a wide variety of sources and who are competitive for twenty-first century careers. (Keats, et al., 2003:9)

With reference to this policy imperative, one of the aims of the e-learning strategy is to address the four digital academic literacies as defined by the e-learning strategy, namely, basic computer literacy, digital information literacy, digital information fluency, and digital knowledge creation. It is envisaged that the e-learning domain will:

support its strategic vision by promoting, enabling, supporting, developing and researching pedagogically effective and innovative uses of ICTS for teaching and learning courses in the institution's courses and programmes. (Stoltenkamp, 2005)

Emanating from the latter, the e-learning concept is used in this paper to describe any learning that is enhanced by access to electronics and learning resources via a computer. In this way e-learning encompasses distance learning via the Internet, but also includes the use of electronics, such as cell phones, video and still cameras, web technologies and $\mathrm{CD}-\mathrm{ROM}$ to enhance more traditional face-to-face learning and to enhance traditional distance delivery mechanisms. 
These technologies are referred to by Collis and Moonen (2008) as second generation web-based services that emphasize online collaboration and sharing; and the technologies have the potential to be used in a rich range of ways to support learning (Gaffar, Singh \& Thomas 2011; Singh \& Gaffar 2011)). Learning through technology is increasingly taking place in diverse environments to teach, mediate and offer many different kinds of media to match the styles and paces of learners. Such media add flexibility to the teaching and learning experience.

This research work explores the use of pedagogical approaches such as artefact production as strategy to enhance teaching and learning at the University of the Western Cape. The background to the research, the methodology, theoretical framework and some preliminary results will be discussed.

\section{Contextual Background to this Study}

The Zoology course was the introductory module offered during the second year of the Biodiversity and Conservation Biology (BCB) programme. The focus of this eight week course is a general introduction to animal diversity. Since electives were introduced during the process of modularization, many non-BCB students registered for it as an elective. The teaching approach is largely seminar-based rather than chalk-and-talk lectures. One of the objectives of the module was to develop students' understanding of taxonomy and systematics. They needed to understand organisms' scientific names, their common names and the evolutionary relationships of the organisms. The learning outcomes included: students had to demonstrate that they were capable of using the internet in searching for relevant information, using the library effectively, they had to use reference books, and during class discussions they were using small group learning strategies. Students had access to a multimedia computer laboratory housed in the department which had access to the internet and email and the necessary software (e.g., PowerPoint or MSP) in order to develop their project presentations. The second -year Zoology course was presented as a hands-on course.

The lecturer's previous exposure and experience with the use of technology in the classroom ultimately led to the use of more sophisticated software in the classroom. This was despite the fact that students in this second-year course had varied levels of computer literacy. Microsoft Producer for PowerPoint 2010 (MSP) allows one to import PPT presentation projects, video, images, html pages and audio, to produce an automated synchronized presentation. The completed presentations can be output either to CD-ROM or DVD or be prepared for streaming over the World Wide Web (WWW). The objective in terms of the technology was to "burn" the completed presentations onto disc and return it to the students as a tangible outcome of their research projects.

When the lectures commenced and surprisingly the expected class of 16 had risen to 50 . We decided to divide the students into ten groups of 5 . For the first time students were assigned to work in groups around a single organism (see Appendix A).

This study was driven by the following research questions:

1. How can one use technology to enhance students' participation in research?

2. How can artefact production be used to positively impact the uptake of subject content?

3. Does artefact production meet the learning objectives of the course?

4. What is a suitable model for the introduction of technology in a teaching-and-learning environment?

This study is foregrounded by Activity theory as it seems best suited for the purpose of conducting this research.

\section{Theoretical Framework}

The study uses Activity theory as theoretical framework. According to Russell (2000), activity theory was developed from the Russian developmental psychologist Vygotsky's (1994) cultural-historical approach to learning by one of his two main collaborators, A. N. Leont'ev (1981), beginning in the late 1930s. The theory articulates learning as an activity that expands over time and both socially and intellectually involving, with people and tools available; learning is beyond the internalization of discrete information or skills by individuals. Consequently, Han and Bhattacharya (2001) describe the value of creating external objects when they explain the value of Learning by Design (LBD). According to the authors, this design process creates a rich context for learning. Learning by Design values both the process of learning and its outcomes or products. The essence of Learning by Design is in the construction of meaning. Designers (learners) create objects or artefacts representing a learning outcome that is meaningful to them. In essence, it appears that to some extent that the Activity theory, LBD and Project-Based-Learning (PBL) share traits with Constructionism. The latter has its roots in Constructivism and is therefore all learner-centred teaching-and-learning approaches. Han, et al. (2001) assert that, 
...constructionism suggests that new ideas are most likely to be created ideas when learners are actively engaged in building some type of external arti(e)fact that they can reflect upon and share with others.

Julie (1998) making a case for artefact production as a goal in school mathematics, defines an artefact as any object constructed for a purpose, and validated within a community of practitioners. Here the term object is not necessarily limited to something concrete or tangible but could even be texts or diagrams. Our understanding is that an artefact is not limited to the final product but includes those accompanying bits and pieces produced while working toward the "end" product or goal. Marsick et al. (2001) relates this phenomenon to the theory of incidental learning, defining it as,

... a byproduct of some other activity, such as task accomplishment, interpersonal interaction, sensing the organizational culture, trial and error experimentation, or even formal learning.

Incidental learning is characterized as follows:

- It is integrated with daily routines

- It is triggered by an internal or external jolt

- It is not highly conscious

- It is haphazard and influenced by chance.

- It is an inductive process of reflection and action.

- It is linked to the learning of others.

A possible criticism of the theory and given the unstructured nature of this approach is that, "without intervention of critical reflection, it is equally possible to hold incorrect as well as correct assumptions" (Marsick \& Watkins, 2001). Furthermore, Conole (2008) emphasizes that learning activities can be 'codified' into a number of different forms of representation, which each foreground different aspects of the learning activity and which provide a means of illustrating the inherent design. These forms of representation are as mediating artefacts because there is emphasis on their mediating role in terms of how they are used to mediate subsequent design activities. The author asserts that mediating artefacts can be aggregated into metamediating artefacts of three main kinds:

- Aggregates. The first type consists of aggregates of example mediating artefacts, for example, repositories of case studies, patterns, or models or a combined repository containing a mixture of all three.

- Scaffolds. The second type consists of scaffolds of some kind (such as FAQs, tips, and hints or guidelines) that synthesise key points and issues.

- Mixed. The third type consists of a mixture of example mediating artefacts and scaffolds or supporting text, such as toolkits and pedagogical planners.

Julie (1998) claims that when artefacts (or byproducts) are not made explicit we are excluding learners from access into a practice and in so doing perpetuate the kind of "treatment that social groupings receive in order to keep them in position of subjugation". This view resonates with that of Britton (1985) who claims that,

Teaching recipes will only help the newcomer to reproduce aspects of his culture, whereas taking part in the social activity that amends the rules or generates new ones allows for the production of cultural forms (p.74).

Julie (1998) further comments that artefact production should be so that there is a "seamless movement between becoming knowledgeable and skilful with tools, artefact production and understanding

In another subject area, Spinuzzi (1999) investigated a group of 13 third-year university students in Community and Regional Planning, who were taking a course in Geographic Information Systems (GIS). The students learnt to use a government computer program that plots traffic accident locations and provides statistics on accidents from data entered by police in their accident reports, late in the course. Despite the fact that some of the students were familiar with other GIS programs, they found it quite challenging to use this program to find information on specific accidents. Initially, it was thought that the challenges being faced by the students were caused by the greater complexity of this program as compared to other GIS programs they had learned. However, by using activity theory, Spinuzzi was guided to trace these problems to the fundamental contradictions in the interface (tool). Hence, the cultural history of this activity system proved crucial in developing improvements in the GIS ALAS interface to help students and new employees learn it. To reduce breakdowns, Spinuzzi had to look beyond training "in the software," to training in the ALAS activity system, its history and institutional uses.

A group of Norwegian researchers employed Activity theory to study the design and use of collaborative telelearning scenarios in the Docta Project of 2000. For this project, Activity Theory gave insights into the processes of 
collaboration, enabling them to identify collaboration patterns as well as understand how instructors, students and other learning facilitators organise their learning and work. One specific study was conducted by Andreassen (2000) by researching a group of three graduate students taking teacher training courses at universities in different cities. The students collaboratively used TeamWave, a web-based shared workspace. The objectives were to learn Salomon's (1992) techniques for creating "genuine interdependence" in work and to use "genuine interdependence" to collaboratively create a web-based learning environment on endangered animal species for primary school science students. Findings revealed that the students did not use the software tools to produce genuine interdependence, a "partnership of collaborating peers," but rather "ganged up on the task." They merely "co-operated" with each other, working individually "to get the whole task over with as easily and fast as possible." Unfortunately, they did not realise the potential of the software for creating genuinely interdependent collaboration.

Another study conducted by Tzeng, Liu, and Lin (2009) examining the application potentials of Web 2.0 tools when integrated in teaching and learning. The study reported that with Web 2.0, information sharing was liberal; it gave room for deep technological penetration and closer links to ordinary life and industrial productivity. Based on this outcome, Tzeng, Liu and Lin (2009) predict that Web 2.0 technologies will become the mainstream talk in business, politics, and military communities, in social fields, and most importantly in education. Hence, they suggest that proper use of these technologies will improve the quality of teaching and learning systems.

\section{Methodology}

\subsection{Research paradigm and design}

We were introduced to the class at the start of the course and even though we didn't start the assignment immediately we felt it was important for us to interact with students and develop a rapport with them. Students got accustomed to seeing the researchers (one was the lecturer) around and discovered that technology formed and integral part of the course. It also gave us a good opportunity to observe some of the classroom dynamics at the start.

\subsection{Data collection and procedures}

During this period of prolonged engagement (during class time, practical periods, out of class research opportunities, day excursions and during the production of the $\mathrm{CD}$ /presentations) further insight was gained in this regard. Feedback from a questionnaire administered at the start of the module indicated that students had varying degrees of computer literacy with some (20\%) never having used PowerPoint (PPT) before. A small percentage (30\%) of students had computers at home and even less had access to still cameras or video cameras. In spite of the limited access to equipment we felt confident that we would be able to provide the necessary support for students to get their assignments done by the deadline.

\subsection{Sampling}

The class was divided into 10 groups of 5 and the instructor attempted to ensure that none of the usual "cliques" (language groups and racial groups) were formed. Each group elected a manager who was tasked to pull the scientific name of an organism out of a hat. Considerations in selecting organisms included, promoting the invertebrate groups, selecting organisms that have been well researched as well as selecting organisms that were not commonly known to all students. The organisms were selected on the basis that they should be relevant to the African learner. It could be endemic to South Africa or Africa in general (see Appendix for examples). They were provided with information on the project (procedures, due dates); the rubric that would be used to assess the project and presentation; information on types and levels of questions, and information on how to develop researchable questions/hypotheses/predictions for their topics.

\subsection{Activity, design and procedures}

The instructor monitored their progress on a weekly basis. They started out by firstly identifying the common name and some general questions or ideas for their project. This initial stage was very interesting. The project-based approach and the fact that they had no clue about the animal before knowing its common name sparked considerable interest. By the second lecture students were very eager to share the common names of the organisms with their classmates (this was 
the assignment). However each group had the common name, their research questions as well as some interesting facts to share with us (for example, among Knysna sea horses the males are impregnated by the females).

Their objective was to develop and answer three researchable questions on their respective animal species. Students were left with the choice of using only PPT or using MSP as presentation tool. We used this approach to accommodate the diverse levels of experience in using technology that existed in the classroom and to increase the learning space. Speaking on learning through variation, Fraser et al. (2004) is of the opinion that,

When the variation is limited, the opportunity for learning is diminished and learning space will be narrow, but when the variation encompasses a number of different aspects of the phenomenon being studied, then the opportunity for learning is expanded and the learning space will be wide (p.225).

Therefore, by simply providing students with different organisms (element of variety) to work with and providing diverse presentation formats we were expanding the learning space.

Students were given access to the dedicated undergraduate teaching laboratory that is equipped with 30 workstations running Windows 2000. In preparation, we had to install MSP and PPT 2010 on all the workstations. Access to the lab was limited to lecture or practical periods. Access outside of these times was problematic as other activities were scheduled for the lab. They were willing to work on their projects on a weekend and we managed to retain the use of the lab one Saturday for the students to work on their assignments. Students were encouraged to save their work either on flash drives or on the special drive reserved for student projects.

As the students progressed with their projects we constantly reminded them of the two main components (artefacts) necessary to complete the MSP which were the PPT and the video clips. Since all students could not be accommodated in the lab simultaneously the practical sessions were conducted with half the class in the practical lab (busy with another practical topic) and the other would work on their project readying it for presentation.

The students' first objective in the process after developing their research questions and collecting information, was to compile their PPT presentations. On completion of the PPT their presentations would be videotaped. Thereafter both video footage and PPT would be imported into MSP for synchronization and editing. The instructor requested students keep the presentations as basic as possible (without animations, etc) to simplify importation into MSP and they were to use only the basic features of MSP to avoid getting bogged down by the technology. The completed projects would be exported for burning onto $C D$. We noticed that the idea of producing the $C D$ as outcome motivated students to complete the project.

Part of the course consisted of field trips to the Aquarium where students were encouraged to collect visual materials for their assignments. Excursions and their educational value have been questioned in the research literature. We noticed that students made connections on field trips with class content as well as with their own projects. Due to the organism assignment students viewed the excursions with purpose and as an integral part of the module.

Students were encouraged to utilize as many resources as possible to gather their information. These included the internet, libraries, video and some conducted their own interviews with academics in the department where no other resources were available For example, the moss frog was researched by interviewing an in-house scientist who is an expert on African frogs.

Once the groups felt comfortable with their PPT presentations, they selected a speaker(s) to do the presentation on camera. Only one group chose to use multiple presenters for their project. Students were asked to schedule meetings with the instructor to set up video-recording sessions. Three of the ten groups elected to do their presentations in the privacy of the researcher's office. At this stage the videos were digitized and uploaded to the streaming server to be downloaded again in the computer lab for incorporation into MSP. The whole digitization process was explained to the students. It was impossible to make these sessions very hands-on due to time constraints. Also, when it came to downloading from the server, we accessed the server ourselfs as we did not want students to access restricted folders at a later stage. The videos were raw footage which meant that most of the editing was left to the students. Some groups opted to do their presentations to the class using the PPT only. Their presentations were recorded on camera for inclusion into MSP at a later stage. There were some technical problems during the presentations which prevented one group from doing their presentation on that day. The lecturer took this into consideration and allowed the group to hand in their presentation at a later date.

Final assessment of their projects involved the project presentation, and in the final objective examination they were asked to rewrite their project idea as a popular article.

Five of the ten groups were interviewed of which two groups completed the MSP. 


\section{Results/Discussion}

Goal six outlined by the strategic academic plan for the University of the Western Cape is to,

Create responsible learners, supported by adequate opportunities for open and resource-based learning. (UWC, 2004:78)

The objectives and results of this study are closely aligned with the above goal. Artefact production has in this instance, not only encouraged students to take responsibility for their own learning by highlighting skills or knowledge they lacked, but also impelled them to seek out solutions. This is in keeping with one of the goals of the e-learning strategy; to make students responsible for their own learning and developing life-long learners. Feedback from interviews conducted with 5 of the 10 groups of students indicates that students found the course content interesting and that the introduction of technology had not interfered with the uptake of subject content. The technology helped with the retention of information by presenting multiple opportunities for interacting with the subject content in different ways. These findings conflates with the view held by Fraser, et al. (2004) in that creating various opportunities for interaction with the same subject provides increased potential for learning. Nearly two weeks after the groups had written their exams they were asked whether they felt comfortable writing on their topics again. They responded with a resounding YES!

An extract from an interview follows:

\section{Q: Why?}

Brenda: It's like something that sticks.

Candice: It's because you continuously do the same thing and you are doing researching basically.

Brenda: Ja, if you are researching things yourself it sticks.

\section{Q: Why do you think that is?}

Brenda: And especially the way that you set it up...It just seems so much easier.

Abbi: I think it sticks because it was more for interest sake. It wasn't like studying. Doing research we found out interesting things about our organism.

\section{Q: What did you find out?}

Abbi: we knew nothing about tortoises.

Brenda: Ja we just thought, "ag slow"... you know that's all (laughing). You don't still think about tortoises and that they can be interesting. You don't expect to find out as much about tortoises.

\section{Q: Did you find that using the technology made learning fun/ exciting or did it hinder your learning?}

Abbi: More exciting. Much more exciting.

Abbi: Working with PPT and setup the information you are going through it again you're organizing the information so that it all flows but you can also add sound effects and time it...

Brenda: You are setting it up in ways that it is interesting for the people you are presenting it to but also for yourself. It kind of helped with the project

These comments made by students illustrate that students were beginning to think about their own learning and how others learn. Confirming this finding, Gaffar, Singh and Thomas (2011) noted that the use of technology allows students to better understand lesson concepts, and provided a reliable means of asking and answering questions. This directly impact on their level of confidence and enhance their zeal to learn. During informal interviews the same students commented on how they were thinking of fonts and colours to use for their presentation which again shows how students moved between digital fluency and digital knowledge creation, aided by media technology.

When asked what their view about technology was after they had completed their projects the same group of students commented:

A: If I have an assignment it would be nice to do it in PPT because it looks much better than just black and white typed out images. It looks a lot more interesting and it feels like you learn more when you do it in PPT.

B: You do! The info sticks for some reason the info just stays there. I am someone that learns something, I have to write a test now so I study for the test and after the test it's over, it's finished. And I mean we did this presentation last term and I still remember what is going on and I remember details and things. 
Students were clearly excited not just about the organisms that they were investigating but also about the new knowledge they were gaining. Despite the fact that students were asked to only use basic software features, there were those who were eager to impress. Some students wanted to include their own music to their presentation and still others wanted to do more animations at the PPT stage. The technology helped sustain and transfer that excitement to the presentations which were noticeable in the excellent class attendance up to the end of the course. Students developed an appreciation not only for the knowledge that was shared but also for the way that knowledge was presented. Drawing a comparison between the live presentations and the ones done with MSP, a member of another group commented:

B: Ours was like just... how can I say... the other's stood there ours was like clean how can I say... there was no of
"MMM ja, you know" and ..."there was none of that it was clear cut no hassle...ja smooth.
Q: So how did that make you feel?!
A: GOOD!!!

Students had a positive attitude change towards the use of technology and their own learning. This is supported by the findings of Tzeng, Liu, and Lin (2009) and Gaffar, Singh, and Thomas (2011:141), that attitude and perception are important indicators of acceptance and subsequent use of any technology. The interaction with the technology allowed for self-evaluation and reflection on the content. This was highlighted from observations made during the MSP production process where members of the groups gave feedback to one another on the correctness of their content. Presenters who did their presentations on-camera for MSP often re-presented their talks until they were satisfied with the results. This afforded learners the opportunity of experiencing themselves as sources of information. All this translates into expanded learning opportunities. Learners often referred to the assignment as being "fun" and that "it didn't really feel like we were studying". It appears that learning for these students was incidental or informal; a byproduct of the research project.

The notion that, internal activities such as thinking, emerge out of practical external activity (Rizzo, 2003 ) rings true for this study as students showed how activities of artefact production (PPT, MSP, CD-ROM etc.) prompted them to think not only about the question posed but also of various ways in which to convey and give creative expression to their new-found knowledge. Students putting together PPT presentations were thinking about which colours and fonts to use in order to make their presentations interesting to the viewer. Since these considerations are influenced largely by their own likes and dislikes, the resultant artefact produced therefore reflects their individual and their culturally defined context. Tools mediate the processes between subject and object; This study has shown that the tools used (PPT, MSP etc.) determine what kinds of interaction were possible and would take place in order to answer the question posed and meet the objective of the assignment. This highlights the importance of selecting the appropriate technology to facilitate the learning process. Technologies such as PPT and MSP give strong visual impact to a well-designed lesson, which can help students in no little way to absorb the content.

This claim is also supported by Conole (2008). Furthermore, the negotiated assigning of tasks within groups determined what interactions took place to achieve the objective.

\section{Conclusion}

This study highlights the potential for using students in the development of MM web-based resources. In an environment where human resources are scarce, and the aim is to cut costs, we should look at employing students as part of the work-force to implementing e-learning and simultaneously impart valuable skills. In so doing, we would contribute to job creation and promote transferable skills.

An added purpose or meaning was given to the assignment through the use of technology. Students were not merely gathering information to answer a question that was posed but were also looking and thinking about the kinds of information they were gathering. Students were able to investigate information at a deeper level at the gathering stage through the use of technology such as cameras and video.

Artefact production needs to be carefully aligned with goals and objectives of the particular course to avoid technology becoming the focus. Offering students a choice of artefacts to produce allows for creativity and adds to the "fun" aspect of learning. In this instance artefact production contributed positively towards students' self-esteem and attitudes towards technology use which created an environment conducive to the uptake of subject content. Artefact production encourages self-reflection as group members criticize and make suggestions regarding improvements to their presentations. The production and delivery of artefacts serves as guides or markers for self-directed learning. 
In addition, communication skills were improved at various levels through interviews conducted with academics, debating within groups as well as communicating using electronics and computer technology. Information literacy skills were increasingly developed over the period of the eight weeks as well - students were able to source information (text, articles, pictures, video or even to create these themselves).

Based on the findings of this study it is apparent that technology alone will not make dull subject content more interesting, for when the so-called "wow-factor" of technology is gone one will still be left with content and that is ultimately what is being assessed. Technology was leveraged to harness skills that form part of a community of practice. The introduction of technology is more amenable when subject content is the stimulus for excitement and the course material is well structured rather than the technology. This approach will reduce the potential risk of having technology become the focus. The fact that students' class attendance was consistent throughout the duration of the course shows a change in attitude towards their own learning.

Through the process of completing the assignment students recognized gaps in the information available on their particular topics as well as gaps in terms of their own computer literacy skills. This was evidenced by students approaching the researchers to source where they could get extra lessons in using PPT. This study also shows that digital academic literacies overlap each other and that the creative use of technology can address the four digital literacies mentioned earlier, within the context of a content course and need not be addressed as a separate computer literacy issue.

Only four out of the ten groups completed their presentations using MSP. The differences in the artefacts produced can be attributed to a combination of factors; the differences in the time that students had available and negotiations within the group as to their choice of presentation format. The group dynamics played an important role in reaching consensus as there were clearly differences of opinion within groups as to which format individuals preferred.

The implication for teaching and learning is that educators need to understand what motivates and excites students and use it as leverage; provide the space where those at the lower and upper end of the pyramid of academic digital literacy can be challenged so as not to lose them either due to frustration or lack of interest. As evidenced by the interviews, it is the content and structuring of the course that provided the stimulus for interesting interactions with content and group members, not technology. Technology was used to exploit that interest by facilitating additional and different interaction with the subject content. Had the subject content been uninteresting the technology could have easily been fore grounded while the content became secondary. This was not the case here as test results and interviews with the students have shown.

\section{Recommendations}

In retrospect there are a number of infrastructural aspects that could be improved to make the implementation process more efficient. Based on some feedback from the students and obstacles encountered the following recommendations are proffered.

a) Increased access to low-cost digital still, and video cameras for student use would allow more students to participate in all aspects of artefact production process. Currently smartphones can fill this gap.

b) Web-cameras with built-in microphones would have given students greater flexibility as to when they would do their on-camera presentations. Smartphones can be used here as well.

c) Greater access to multimedia equipped computer labs would have enabled students who needed more time to improve on their projects and presentations.

d) Opting for free and open source alternatives will enable learners to install software on home computers at no cost and enable them to work on projects outside of classroom time.

Although the study was undertaken in a face-to-face classroom, the results can be applied to e-learning situations supported by Web technologies. This can be achieved by creating artefacts that can be viewed and manipulated in a web browser by providing online tools to facilitate their creation and use. Currently, cloud-based computing enables such learning situtations. Assessment and feedback can be provided in a similar fashion. Software has certain affordances; certain software lends itself to certain teaching-and-learning methods. In this instance, MSP's pack-and-go capacity allows incomplete projects to be "packed" and moved to another computer for completion. This capability makes it a suitable tool for use in an online environment for a collaborative teaching-and-learning approach. 


\section{Acknowledgments}

This is dedicated to the students who participated in this study as well as the pioneers for this course. We would like to acknowledge the funding received by the National Research Foundation of South Africa. Thuthuka Grant number: TTK2008061700005.

\section{References}

Andreassen, E. F. (2000). Evaluating how students organise their work in a collaborative telelearning scenario: An activity theoretical perspective. Masters dissertation, Department of Information Science, University of Bergen.

Conole, G. (2008). Capturing practice: the role of mediating artefacts in learning design in

Lockyer, L., Bennett, S., Agostinho, S. and Harper, B. (eds) Handbook of Research on Learning Design and Learning Objects: Issues, Applications and Technologies, pp.187-207, Hersey, PA, IGI Global. http://www.gsic.uva.es/wikis/yannis/images/d/d2 /Conole_08.pdf

Collis, B., \& Moonen, J. (2008). Web 2.0 tools and processes in higher education: quality perspectives. Educational Media International, 45(2), pp. 93-106.

Docta Project (2000). Design and Use of Collaborative Telelearning Artifacts. Department of Information Science, University of Bergen, Norway. 28 November, 2000. http://www.ifi.uib.no/docta/index.html

Fraser, D. , Linder, C \& Pang, M.F. (2004) Learning Through Variation, Part 1: A Pedagogical Tool, in Buffler, A. \& Laugksch, R.C. (Eds.) (2004). Proceedings of the 12th Annual Conference of the Southern African Association for Research in Mathematics, Science and Technology Education. Durban: SAARMSTE.

Gaffar, K. , Singh, L. and Thomas, T. (2011). Are we ready for web 2.0? Evidence from a Caribbean university. Caribbean Teaching Scholar. 2(1): 129-146.

Goldman, S., Cole, K. \& Syer, C. (1999). The Technology and Content Dilemma. In The Secretary's Conference on Educational Technology http://www.ed.gov/technology/Techconf/1999 (accessed 21 August 2001).

Han, S. \& Bhattacharya, K. (2001). Constructionism, Learning by Design, and Project-based

Learning. In M. Orey (Ed.), Emerging perspectives on learning, teaching, and technology. Available Website:http://www.coe.uga.edu/epltt/LearningbyDesign.htm

Holtman,L. B. (2004). The Organism Project. June18 2010. Working paper: UWC, Bellville

Julie, C. (1998). The production of artefacts as goal for school mathematics? In: A. Olivier \& K. Newstead ( Eds.), Proceedings of the $22^{\text {nd }}$ Conference of The International Group for the Psychology of Mathematics Education. Stellenbosch, South Africa: University of Stellenbosch.

Keats, D., Meerkotter, D., O' Donoghue, K., Tapscott, C., Tise, E., van Bever Donker, J., Venter, I., Walters, s., Wood, T. (2003). An elearning Strategy for the University of the Western Cape.

Marsick, V. \& Watkins, K. (2001). Informal and incidental Learning. New Directions For Adult and Continuing Education, no.89

Marsick, V. \& Watkins, K. (2001). Informal and Incidental Learning. In: New Directions For Adult and Continuing Education, no. 89, Spring. Jossey-Bass, John Wiley \& Sons, Inc.

Russell, D.R. (2000). Looking Beyond the Interface: Activity Theory and Distributed Learning. In Understanding Distributed Learning. Ed. Mary Lea. London: Routledge, 2001. 64-82.271

Spinuzzi, C. (1999). Designing for lifeworlds: Genre and activity in information systems design and evaluation. lowa State University. http://english.ttu.edu/spinuzzi/spinuzzi-dissertation.pdf

Stoltenkamp, J. (2005). The integration of information and communication technologies (ICT) to enhance teaching-and-learning, research, support \& development. Working paper: UWC, Bellville. University of the Western Cape (draft) Strategic Academic Plan 2005-2009

Tzeng, R., Liu, S., \& Lin, W. (2009). A study of a web 2.0-based educative platform. Journal of Systematics, Cybernetics and Informatics, 7(4), pp.38-43. 
Appendix A: List of Organisms

Scientific name of organism

Sardinops sagax

Hippocampus capensis

Hyperolius viridiflavus

Arthroleptella villiersi

Crysaora hysoscella

Potamonautes perlatus

Delphinus capensis or D. delphis

Diogenes brevirostris

Spheniscus demersus

Psammobates geometricus

Promerops cafer

Apis mellifera

Holothuria cinerascens

Anopheles melanogaster

Lycaon pictus

Gallus domesticus

Euplectella

Hirudo medicinalis

Homopus aerolatus

Naja nivea

Struthio camelus

Panthera leo

Pholcus phalangioides

Drosophila melanogaster

Princeps demodocus demodocus common name

Sardine

sea horse

anuran frog

moss frog

schyphozoan

freshwater crab

long/short-beak dolphin

hermit crab

jackass penguin

geometric tortoise

cape sugarbird

honeybee

sea cucumber

mosquito

wild dog

domestic fowl

venus flower basket

medicinal leech

padloper

Cape cobra

camel

lion

daddy longlegs

fruit fly

citrus swallowtail (butterfly) 